\title{
VIIRS on-orbit optical anomaly - Investigation, analysis, root cause determination and lessons learned
}

\author{
Glenn Iona ${ }^{\mathrm{a}}$, James Butler ${ }^{\mathrm{a}}$, Bruce Guenther ${ }^{\mathrm{b}}$, Larissa Graziani ${ }^{\mathrm{c}}$, Eric Johnson ${ }^{\mathrm{d}}$, Brian Kennedy ${ }^{\mathrm{e}}$, \\ Craig Kent ${ }^{\mathrm{b}}$, Robert Lambeck ${ }^{\mathrm{f}}$, Eugene Waluschka ${ }^{\mathrm{a},}$ Xiaoxiong Xiong ${ }^{\mathrm{a}}$ \\ ${ }^{a}$ NASA/Goddard Space Flight Center, Greenbelt, Maryland 20771 \\ ${ }^{\mathrm{b}}$ Stellar Solutions, Inc. (United States) \\ ${ }^{\mathrm{c}}$ SGT, Inc. (United States) \\ ${ }^{\mathrm{d}}$ Raytheon, Space and Airborne Systems (United States) \\ ${ }^{\mathrm{e}}$ Kennedy Consulting, Inc. (United States) \\ ${ }^{\mathrm{f}}$ MEI Technologies, Inc. (United States)
}

\begin{abstract}
A gradual, but persistent, decrease in the optical throughput was detected during the early commissioning phase for the Suomi National Polar-Orbiting Partnership (SNPP) Visible Infrared Imager Radiometer Suite (VIIRS) Near Infrared (NIR) bands. Its initial rate and unknown cause were coincidently coupled with a decrease in sensitivity in the same spectral wavelength of the Solar Diffuser Stability Monitor (SDSM) raising concerns about contamination or the possibility of a system-level satellite problem.

An anomaly team was formed to investigate and provide recommendations before commissioning could resume. With few hard facts in hand, there was much speculation about possible causes and consequences of the degradation. Two different causes were determined as will be explained in this paper. This paper will describe the build and test history of VIIRS, why there were no indicators, even with hindsight, of an on-orbit problem, the appearance of the on-orbit anomaly, the initial work attempting to understand and determine the cause, the discovery of the root cause and what Test-As-You-Fly (TAYF) activities, can be done in the future to greatly reduce the likelihood of similar optical anomalies. These TAYF activities are captured in the "lessons learned" section of this paper.
\end{abstract}

Keywords: NPP, VIIRS, Degradation, MODIS, Tungsten, Radiation, Contamination, lessons learned

\section{INTRODUCTION}

Over the last dozen years, NASA has launched a series of satellites - known collectively as the Earth Observing System (EOS) - that has provided critical insights into the dynamics of the entire Earth system: clouds, oceans, vegetation, ice, solid Earth and atmosphere. The Joint Polar-Orbiting Satellite System (JPSS) is the next generation of NASA/NOAA satellites whose mission is to extend and improve upon the Earth system data records and weather prediction.

The SNPP mission, a comprehensive risk reduction phase for the JPSS program, is designed to demonstrate a fully functional satellite with several newly developed sensors, including command, control and data processing ground systems. Continuity of EOS sensor data sets was another significant objective for NASA with this mission ${ }^{1}$. Two SNPP sensors, the Advanced Technology Microwave Sensor (ATMS) and the Cross-track Infrared Sensor (CrIS) were designed as meteorology sensors. These are the follow-on sensors continuing the research of the microwave and infrared sensors on the NASA Aqua mission.

Another SNPP sensor, VIIRS produces 20 of 25 key Environmental Data Records (EDRs) and its performance is critical to maintain continuity from EOS heritage observations. For this and other reasons VIIRS was designed with strong heritage to the Moderate Resolution Imaging Spectroradiometer (MODIS), which is currently operating on-board the NASA's EOS Terra and Aqua spacecraft, launched in December 1999 and May 2002, respectively. VIIRS 
observations are made in 22 spectral bands ${ }^{2}$, including 14 reflective solar bands (RSB), 7 thermal emissive bands (TEB), and 1 day-night band (DNB), covering wavelengths from 0.41 to $12.5 \mu \mathrm{m}$ (micrometers). By comparison, MODIS collects data in 36 spectral bands, 20 RSB and 16 TEB, covering the spectral range from 0.41 to $14.5 \mu \mathrm{m}$. The Longwave Infrared (LWIR) sounding channels (bands) in MODIS were not included in the VIIRS design, partially due to the fact that observations at these wavelengths are provided by the CrIS sensor operated on-board the SNPP and future JPSS satellites. In addition, VIIRS has a Day Night Band (DNB) with a spectral range from 0.5 to $0.9 \mu \mathrm{m}$. Depending on the earth view targets (surface types), high or low-gain observations can be made by 7 VIIRS spectral bands.

MODIS observations are made at 3 different spatial resolutions (nadir): $250 \mathrm{~m}$ (2 bands), $500 \mathrm{~m}$ ( 5 bands), and $1 \mathrm{~km}$ (29 bands), while VIIRS was designed with spatial resolutions of $375 \mathrm{~m}$ for its imaging bands (I bands) and $750 \mathrm{~m}$ for the moderate resolution bands ( $\mathrm{M}$ bands).

MODIS and VIIRS carry a set of on-board calibrators (OBC), comprising a solar diffuser (SD) and a solar diffuser stability monitor (SDSM) for RSB calibration and a blackbody (BB) for TEB calibration. VIIRS OBC design was largely based on the design and improvements made from the MODIS OBC. One of the MODIS OBC, the spectroradiometric calibration assembly (SRCA), was not included in the VIIRS design. The SRCA provides on-orbit spectral and radiometric characterization for the visible (Vis) through short-wave infrared (SWIR) bands, and spatial characterization for all the spectral bands on the MODIS sensor. Figure 1 shows the various optical components of the VIIRS design. Those components that have evolved or have heritage from MODIS are asterisked in Figure 1. Figure 2, courtesy of Ball Aerospace, illustrates SNPP sensor placement on the spacecraft nadir (earth-viewing) mounting deck.

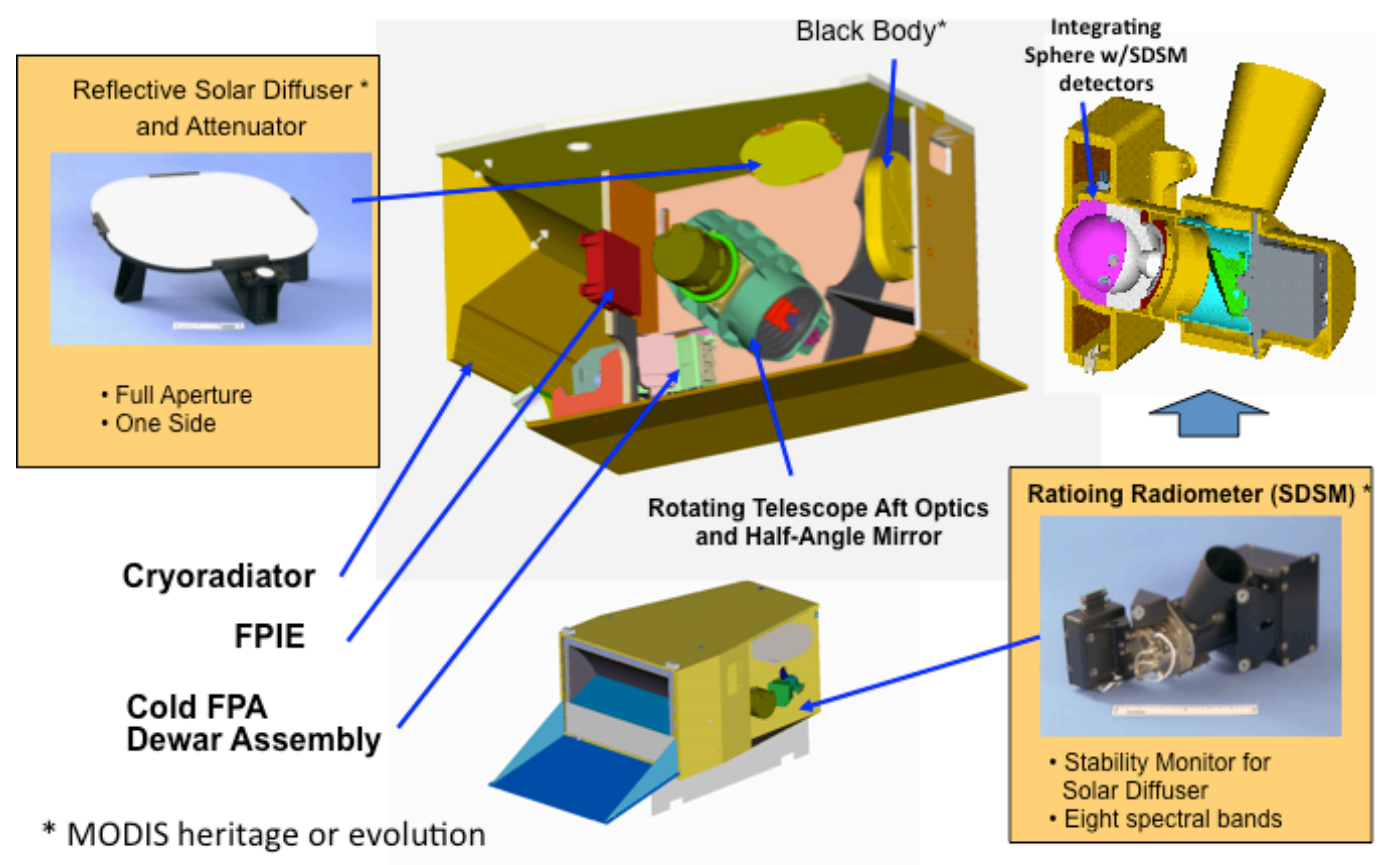

Figure 1: VIIRS optical system components

Like MODIS $^{3,45,6,7}$, VIIRS performed extensive pre-launch measurements in order to calibrate and characterize sensor radiometric, spectral, and spatial performance. Key radiometric measurements were made in different operational configurations (e.g. primary and redundant power supplies and control electronics) and conditions (e.g. cold, nominal, and hot thermal vacuum (TVAC) temperature plateaus and different cold focal plane temperatures). Most of the ground test equipment and calibration sources were developed and built for the MODIS program. These Ground Support Equipment (GSE) tools were carefully examined and evaluated (re-certified) prior to their use for VIIRS calibration and characterization. Major improvements made for VIIRS pre-launch calibration included Visible / Near-Infrared 
(VisNIR) In Band (IB) and Out Of Band (OOB) relative spectral response (RSR) characterization using laser-based calibration sources from National Institute of Standards and Technology (NIST) ${ }^{8}$, polarization sensitivity measurements using a full aperture linear polarizer sheet with an integrating sphere source ${ }^{9}$, and limited end-to-end testing of the RSB OBC system at the observatory (i.e., satellite) level ${ }^{10}$.

Early spatial characterization testing for VIIRS demonstrated that the interference filter assembly angle for the VisNIR bands has an angle resolved scatter characteristic that may lead to a high sensitivity to spectral cross-talk in the sensor ${ }^{11}$. These tests demonstrated also that the spectral out of band and cross-talk data might be sensitive to the state of polarization of the incident atmospheric data. Special testing was performed as part of the laser-source spectral characterization and results indicate that the actual sensor on-orbit spectral cross-talk is small and well within the ranges of cross-talk observed on earlier sensors ${ }^{12}$.

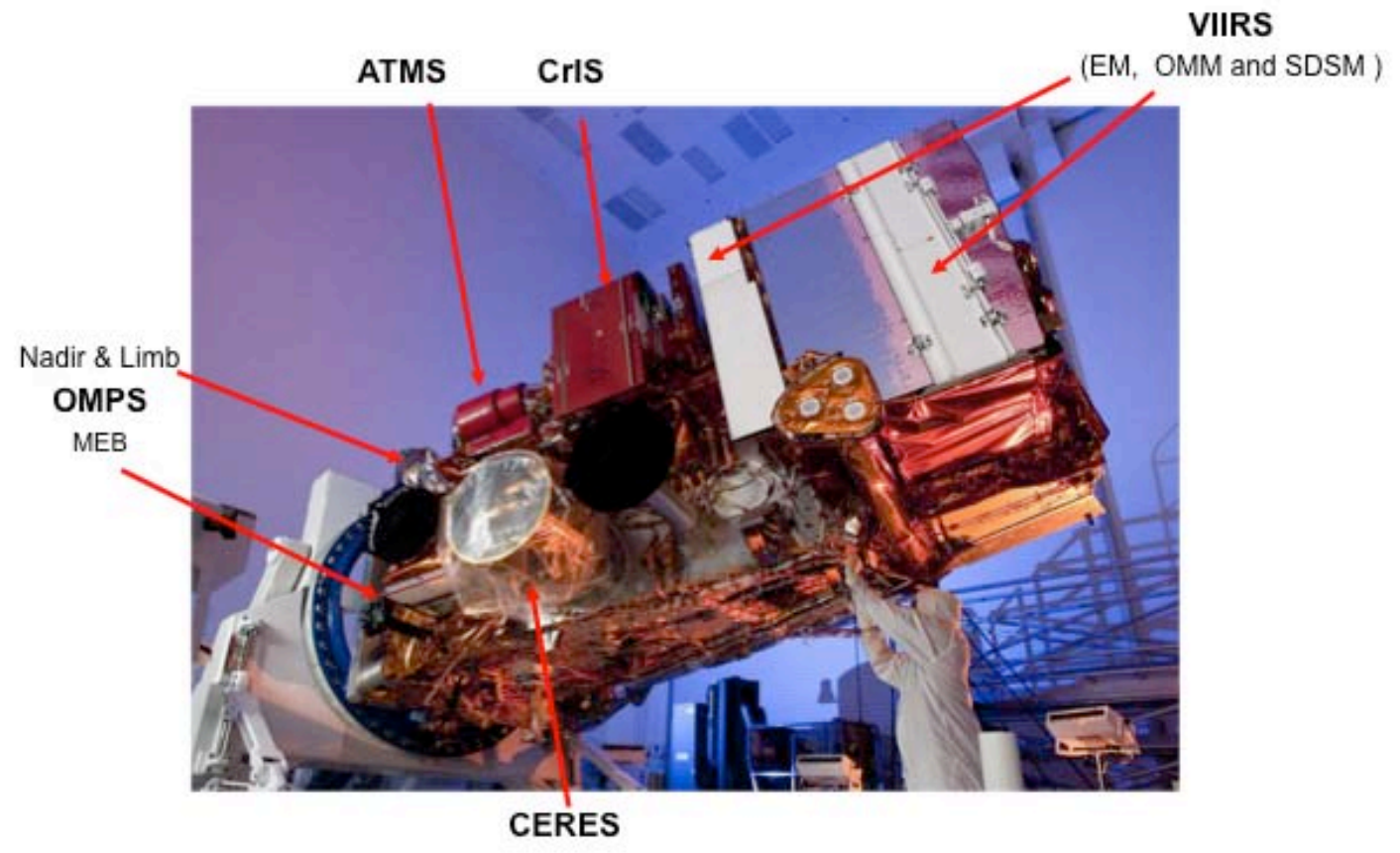

Figure 2 : SNPP sensor placement on the spacecraft nadir, earth-viewing, deck with protective covers while in the cleanroom. Photo courtesy of Ball Aerospace

\section{ANOMALY AND COMMISSIONING CHALLENGES}

SNPP was launch on October 28, 2011. Spacecraft and sensor commissioning activities proceeded per the pre-launch timeline with only minor deviations and anomalies through November. In accordance with the commissioning timeline, VIIRS was powered on November $8^{\text {th }}$ and the nadir earth-view aperture doors were opened on November $21^{\text {st }}$ after the sensor initial outgassing was completed. The science team analyzed these data and on December $7^{\text {th }}$ reported a persistent degradation in the VisNIR bands and the DNB above 600 nanometers (nm) that accelerated significantly after the nadir doors were opened. Figure 3 shows the VIIRS persistent response degradation of VisNIR bands as a function of solar UV exposure time ${ }^{1}$. The VIIRS VisNIR degradation was closely correlated with UV exposure of the fore-optics and thus the degradation appears to be a smooth function when plotted as a function of UV exposure time. Based on MODIS experience, the degradation in response to the SD is expected to be larger at the shorter wavelengths primarily due to degradation of the SD reflectance, in contrast to what was observed on VIIRS.

The early investigation revealed similar spectral dependent response degradation above $650 \mathrm{~nm}$ in the SDSM, which has its own optical system (fore-mirror to detectors) separate from the VIIRS sensor. The VIIRS VisNIR/DNB and SDSM optical paths do share a common view of the SD, but didn't exhibit the same degradation in the NIR region. Figure 4 illustrates the different optical paths for VIIRS. The VIIRS optical components of interest in the anomaly 
investigation are shown in Figure 1.

Early in the investigation, the spectral signatures of common contaminants (e.g. silicone, hydrocarbon) were found to not match the observed VIIRS degradation, since they would degrade spectral performance below $600 \mathrm{~nm}$ (e.g., similar to the MODIS SD degradation). The spectral signature did match that of soft metals (e.g. cadmium and mercury) but it was difficult to postulate a source in close proximity to the two different optical paths to cause the observed degradation. There was also much speculation as to whether the contamination was localized to VIIRS or global in nature. Similarly, it was unclear if the observed degradation was from a single or multiple sources. Given the unknowns and close proximity of VIIRS to the other SNPP sensors, see Figure 2, the remaining sensor commissioning activities were put on hold indefinitely.

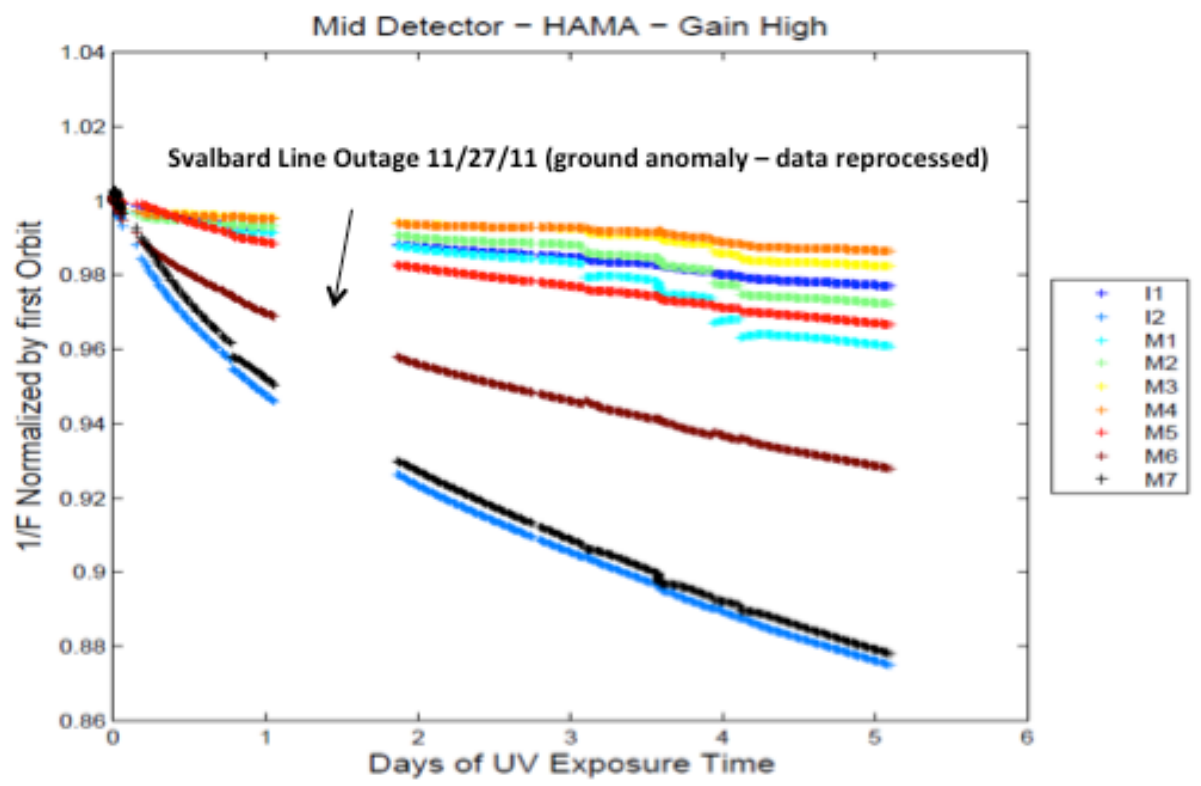

Figure 3: Accelerated and continued degradation of VIIRS VisNIR band throughput

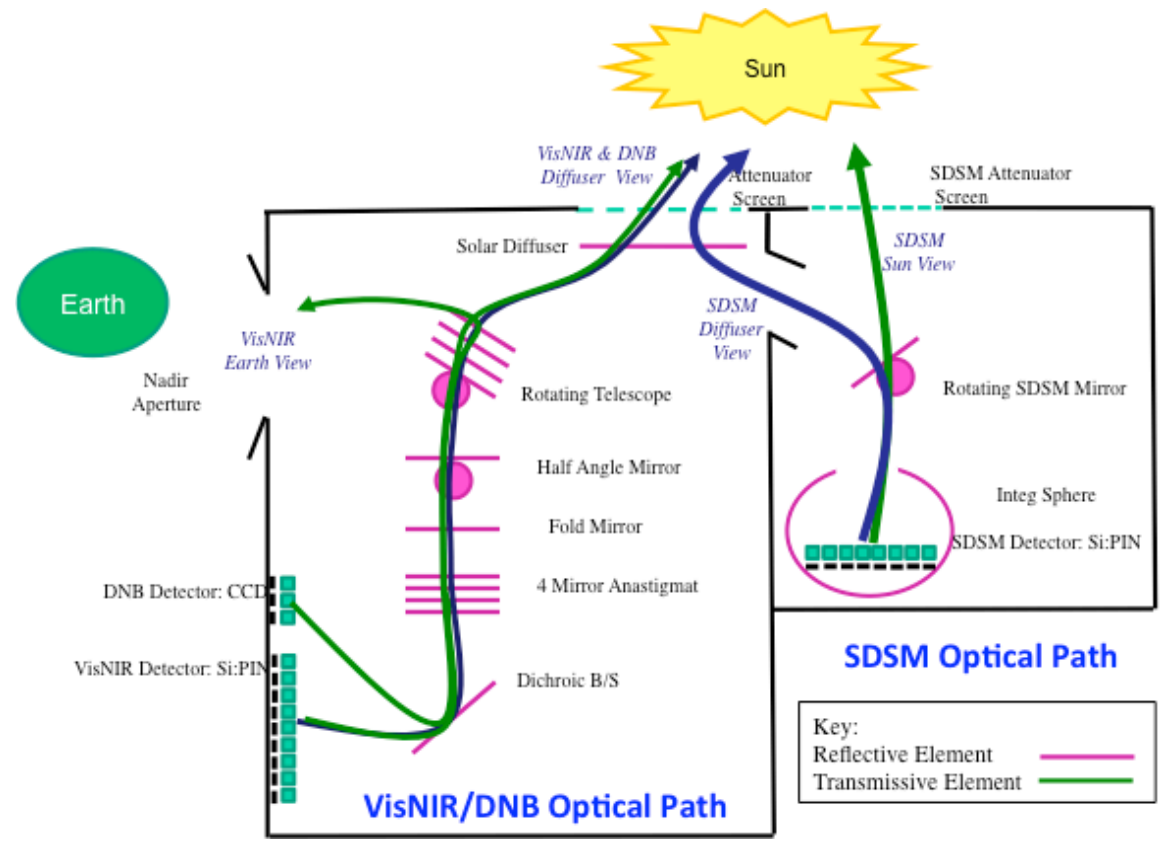


Figure 4: VIIRS VisNIR/DNB and SDSM optical paths

\section{ANOMALY INVESTIGATION}

With few hard facts, there was much speculation about possible causes and consequences of the degradation. Therefore, an Anomaly Resolution Team (ART) was convened to define a multifaceted approach to gain additional insight to quantify the risk to all sensors and to outline a revised plan for completing the sensor commissioning activities.

At the time of the anomaly discovery, all sensors were powered and their outgassing completed, if applicable. All sensor earth and space views were closed in their launch configuration, with a few exceptions. ATMS was the first operational sensor collecting imaging data. However, ATMS is relatively insensitive to molecular contamination and thus could not provide additional forensics into the anomaly. VIIRS had recently opened its nadir earth-view doors but the cryo-radiator cooler door was closed. The next step in the commissioning plan was to open the VIIRS and CrIS cooler apertures to cold space. This would have been an excellent discriminator given both coolers are sensitive to molecular contamination. The risk of further spreading the contamination and limited ability to outgas cooler contaminants led to suspension of these activities until further information could be gathered on the risk to the cooler performance and mission science performance.

With these restrictions and limited insight to the cause of the observed degradation, the ART needed to find other ways to discriminate between multiple possible causes. The ART defined an Anomaly Decision Flow for assessing the commissioning risk, as shown Figure 5.

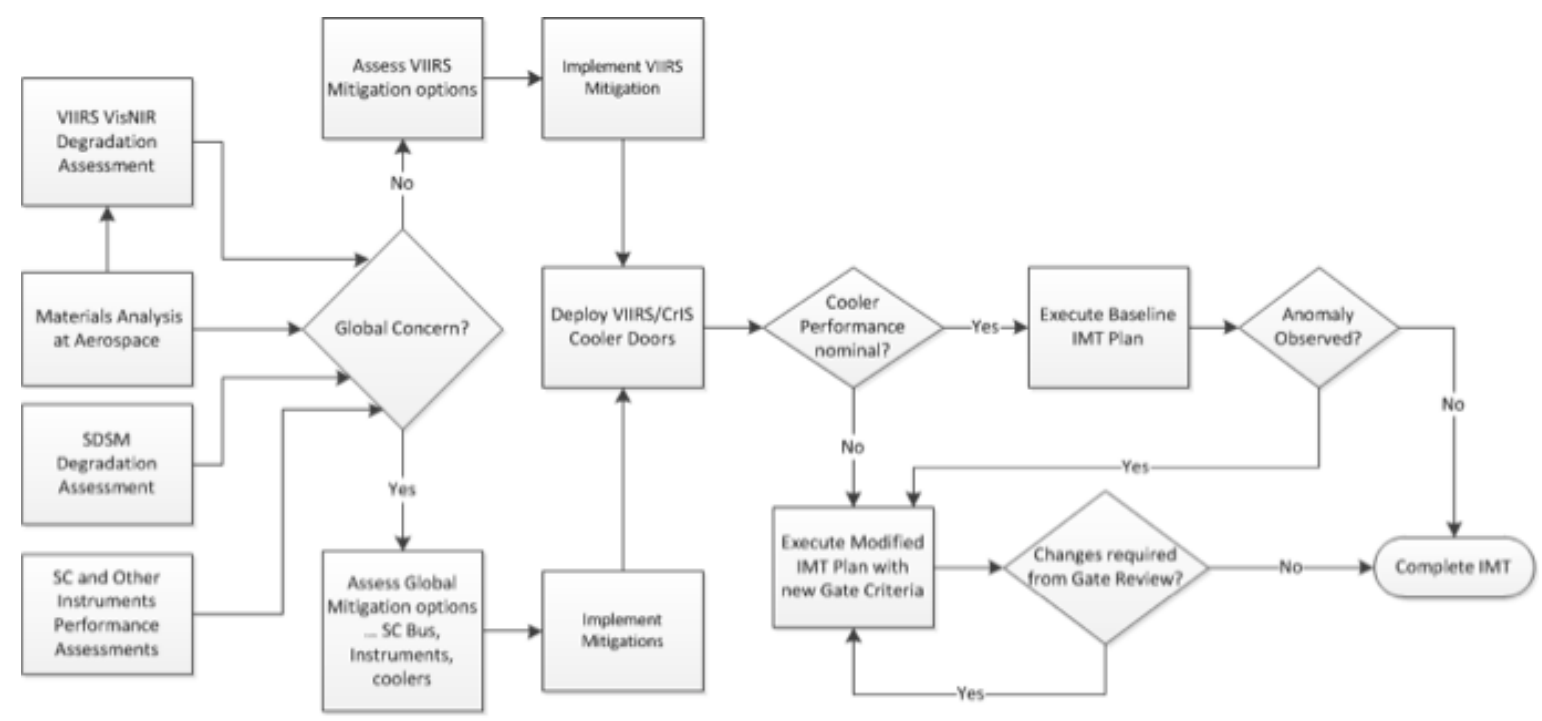

IMT - Integrated Mission Timeline for satellite commissioning activities

Figure 5: Anomaly decision flow for assessing the commissioning risk

The ART also followed a multifaceted approach to gain additional insight to quantify the risk to all sensors and to outline a revised plan for completing the remaining sensor commissioning activities. This plan included

1. Rounding up of additional project and non-project government and contractor experts for VIIRS, optics, detectors, contamination, radiation, materials, data analysis, science, mission assurance, and systems

2. Forming VIIRS technical anomaly team to focus on special tests to better characterize of the VIIRS on-orbit degradation along each optical path. They also performed data analysis and action item tracking

3. Forming contamination team to coordinate witness sample testing and to research possible contamination sources that matched the observed spectral signature.

a. The Aerospace team led witness sample testing for VIIRS, Clouds and the Earth's Radiant Energy System (CERES), and control samples; including VIIRS samples from the flight sensor Rotating 
Telescope Assembly (RTA) mirror coating run

4. Forming a satellite and sensor special test team to evaluate sensor / spacecraft special tests and review of prelaunch documentation for any possible signs or causes

5. Involving various science team members from Raytheon, NASA, NOAA, Aerospace corporation, and others for data analysis and trending

6. Holding a VIIRS Deep Dive Face-to-Face meeting to review the optical design, materials, process, testing, and build history. This also allowed those unfamiliar with VIIRS to understand the design

7. Performing a site visit to the mirror coating manufacturer Denton (now Quantum)

The ART held weekly tag up meetings to coordinate and discuss the progress, theories and results from the parallel test, analysis and data trending activities. In addition, the various Subject Matter Experts (SMEs) researched and met in smaller groups to discuss observables, prior test history, and possible theories on a variety of potential contamination sources that matched the spectral signature.

The Raytheon team supporting the ART, defined special diagnostic tests for VIIRS that could be performed on-orbit to better characterize and discriminate the degradation in the VisNIR and SDSM optical paths. Table 1 outlines the VIIRS special tests performed and a summary of the conclusions or findings ${ }^{13}$.

Table 1: VIIRS special tests performed on-orbit

\begin{tabular}{|c|c|c|}
\hline Test Activities & Objective & Conclusions / Findings \\
\hline $\begin{array}{l}\text { VIIRS Special Tests \#1 } \\
\text { (RTA/SDSM stowed } 3 \text { days) }\end{array}$ & $\begin{array}{l}\text { - Evaluate rate of degradation for } \\
\text { VIIRS/SDSM (RTA stowed } \\
\text { eliminating optics Ultra-Violet } \\
\text { (UV) exposure }\end{array}$ & $\begin{array}{l}\text { - VIIRS NIR degradation returned to } \\
\text { slower decay } \\
\text { - SDSM NIR degradation continued at } \\
\text { same rate }\end{array}$ \\
\hline $\begin{array}{l}\text { VIIRS Special Tests \#2 (RTA } \\
\text { stowed in daylight, Night Obs } \\
\text { with Solar Cals) }\end{array}$ & $\begin{array}{l}\text { Minimize light on VIIRS optics } \\
\text { to discriminate between solar } \\
\text { and other contamination effects } \\
\text { while providing trend data }\end{array}$ & $\begin{array}{l}\text { - VIIRS NIR degradation returned to } \\
\text { slower decay } \\
\text { - SDSM NIR degradation continued at } \\
\text { same rate } \\
\text { - Active contamination source unlikely } \\
\text { to be the cause }\end{array}$ \\
\hline $\begin{array}{l}\text { VIIRS Special Tests \#3 (long stow } \\
\text { of RTA/SDSM } \sim 1 \text { week) }\end{array}$ & 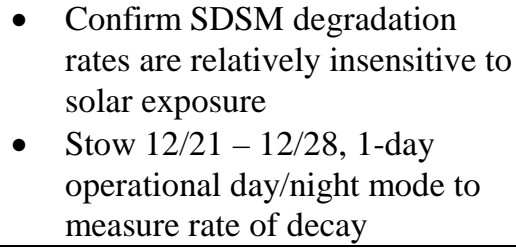 & $\begin{array}{l}\text { - VIIRS NIR degradation returned to } \\
\text { slower decay } \\
\text { - SDSM NIR degradation confirmed not } \\
\text { to be UV related as it continued to } \\
\text { decay at the same rate }\end{array}$ \\
\hline $\begin{array}{l}\text { VIIRS Special Tests \#4 (short } \\
\text { stow of RTA/SDSM not operating } \\
\sim 4 \text { days) }\end{array}$ & $\begin{array}{l}\text { - Stow } 12 / 29-1 / 2 \text { to halt } \\
\text { degradation while we awaited } \\
\text { the Aerospace witness sample } \\
\text { results }\end{array}$ & $\begin{array}{l}\text { - VIIRS NIR degradation returned to } \\
\text { slower decay } \\
\text { - SDSM NIR degradation continued at } \\
\text { same rate }\end{array}$ \\
\hline
\end{tabular}

The VisNIR degradation observed during these special tests was trended as shown in Figure 6. The conclusions of these activities were

- $\quad$ The rate of NIR response degradation significantly increased with nadir door opening on November 21, 2012. Note discontinuity in trend for NIR bands (M7/I2, M6, M5)

- The NIR degradation paused when in darkness or stowing telescope, stopping UV exposure.

- The degradation of short wavelength bands (M1-M3) remained relatively constant through stows and strongly correlated with the drop in SD reflectance measured by SDSM.

Similarly, the SNPP Project system team identified on-orbit tests or analysis that could be carried out by the OMPS, CERES and spacecraft contractor teams. The activities were selected based on similarity of their spectral range coverage to the VIIRS NIR bands or whether their system components performance could be impacted by 
contamination (e.g., sun sensors, thermal performance, or power changes). These activities were scheduled asynchronous with the VIIRS special tests. The results are summarized in Table 2 and 3 . The results of these tests did not support the global contamination theory. However, CERES did observe a similar degradation with their Silicon p-n junction (PIN) photodiodes consistent with previous missions. They attributed this to known behavior associated with the radiation environment. The 2 times rate observed on SNPP CERES is consistent with the $\sim 2 \mathrm{x}$ radiation environment for SNPP when compared to prior EOS CERES missions. This behavior also matches the VIIRS SDSM response degradation. The similarity supported an alternate degradation source for the SDSM separate from the VisNIR degradation.

Table 2: Sensor special tests

\begin{tabular}{|c|c|c|}
\hline Test Activities & Objective & Conclusions / Findings \\
\hline $\begin{array}{l}\text { OMPS Special } \\
\text { Tests On-orbit }\end{array}$ & $\begin{array}{l}\text { 1. OMPS LED Lamp (at } 810 \mathrm{~nm} \text { - trending } \\
\text { with door } \\
\text { 2. Solar Cals with diffuser in place to evaluate } \\
\text { performance trending ( } 3 \mathrm{~m}, 50 \mathrm{~m}, 3 \mathrm{~m} \text { ) } \\
\text { 3. Limb Earth view } 2 \text { consecutive orbits; } 1 \\
\text { orbit includes lunar view } \\
\text { 4. Nadir first series of } 11 \text { solar cals each } 6 \text { min } \\
\text { planned for } 1 / 10 \\
\text { 5. Series of Limb/Nadir solar and earth view } \\
\text { collects planned to evaluate performance }\end{array}$ & $\begin{array}{l}\text { 1. LED lamp 2\% change highly correlated } \\
\text { with temperature variations } \\
\text { 2. Significant, wavelength-independent } \\
\text { changes observed correlated with } \\
\text { calendar time. High probability changes } \\
\text { are goniometry errors. Based on } \\
\text { comparable exposure of the Limb } \\
\text { diffuser, OMPS is no longer concerned } \\
\text { about excessive UV degradation } \\
\text { 3. no degradation seen } \\
\text { 4. no degradation seen } \\
\text { 5. no degradation seen }\end{array}$ \\
\hline $\begin{array}{l}\text { CERES Special } \\
\text { Tests On-orbit }\end{array}$ & $\begin{array}{l}\text { 1. Evaluate Sun Presence Sensors (SPS) and } \\
\text { radiator trending data for any changes. SPSs } \\
\text { oriented with } 1 \text { cold and } 1 \text { viewing sun } \\
\text { 2. Evaluate Thermal performance of radiators } \\
\text { 3. Evaluate CERES internal calibrations for } \\
\text { differences from prior CERES sensors } \\
\text { 4. CERES lifetime (Mar } 2009 \text { - Sept 11) } \\
\text { witness sample contamination analysis } \\
\text { (ToF-SIM, Solar UV tests) }\end{array}$ & $\begin{array}{l}\text { 1. Higher change in SPS response is likely } \\
\text { attributable to the increased radiation } \\
\text { environment ( } 2 \mathrm{x} \text { Total Ionizing Dose) } \\
\text { 2. No evidence of degraded thermal radiator } \\
\text { performance } \\
\text { 3. Internal calibration results are consistent } \\
\text { with prior flight sensors. CERES SW } \\
\text { Silicon PIN photodiode (PD) decay } \\
\text { consistent with expectations based on } \\
\text { high energy particles } \\
\text { 4. CERES lifetime witness sample does not } \\
\text { show UV sensitivity or contamination }\end{array}$ \\
\hline
\end{tabular}

Table 3: Spacecraft special tests

\begin{tabular}{|l|l|l|}
\hline Test Activities & \multicolumn{1}{|c|}{ Objective } & \multicolumn{1}{c|}{ Conclusions / Findings } \\
\hline $\begin{array}{l}\text { Solar array } \\
\text { peak power }\end{array}$ & $\begin{array}{l}\text { - Evaluate changes in peak } \\
\text { power out of eclipse }\end{array}$ & $\begin{array}{l}\text { - Solar array output increase is accounted for in the changes in } \\
\text { beta angle and solar factor }\end{array}$ \\
\hline $\begin{array}{l}\text { Star tracker } \\
\text { trending }\end{array}$ & $\begin{array}{l}\text { - Evaluate star tracker } \\
\text { telemetry trending } \\
\text { performance }\end{array}$ & $\begin{array}{l}\text { - ADCS does not see anything in the number of stars tracked, the } \\
\text { background level, or the temperatures that might indicate a } \\
\text { change in the tracker performance due to contamination }\end{array}$ \\
\hline $\begin{array}{l}\text { Satellite Review } \\
\text { of Post TVAC } \\
\text { activities }\end{array}$ & $\begin{array}{l}\text { - Identify materials and } \\
\text { processes used for post } \\
\text { TVAC activities }\end{array}$ & - No indication activities could be source of contamination \\
\hline $\begin{array}{l}\text { SC thermal } \\
\text { trending } \\
\text { (Heater duty } \\
\text { cycle and } \\
\text { radiator temps) }\end{array}$ & $\begin{array}{l}\text { Evaluate changes in } \\
\text { heater duty cycles and } \\
\text { radiator temperatures }\end{array}$ & $\begin{array}{l}\text { - Reviewed flight thermal data through December and there was } \\
\text { no evidence of thermal degradation attributable to } \\
\text { contamination. This was based on four flight thermistors } \\
\text { measuring fin temperatures. Locations were selected because } \\
\text { they are most likely to observe degradation because of the large } \\
\text { surfaces and are directly exposed to the surrounding }\end{array}$ \\
\hline
\end{tabular}




\begin{tabular}{|l|l|l|}
\hline & & $\begin{array}{l}\text { environment. After the first 10 days of commissioning we } \\
\text { haven’t measured any real temperature change on these surfaces. }\end{array}$ \\
\hline $\begin{array}{l}\text { Solar Array } \\
\text { Cert Log } \\
\text { History }\end{array}$ & $\begin{array}{l}\text { • Look of any source of } \\
\text { outgassing materials }\end{array}$ & $\bullet$ No indication activities could be source of contamination \\
\hline
\end{tabular}

The on-orbit VisNIR degradation suggested contamination along the optical path. This was supported by a uniform degradation across all the VisNIR and DNB detectors within a given spectral band, as noted in Figure 4. Given the dramatic change observed after the nadir doors opened, it suggested that the optical components affected likely had a view of earth albedo and direct/indirect solar UV energy. Special testing of mirror witness samples was performed at the Aerospace corporation given their involvement in VIIRS program, their experience with testing of silver coated mirrors, and the Space Environmental Effect (SEE) facility where they can perform Time-of-Flight Secondary Ion Mass Spectrometry (ToF-SIM) sputter analysis. The ToF-SIM was first performed with the VIIRS witness sample that followed the sensor (RTA \#1). Later ToF-SIM was performed on a pristine VIIRS RTA mirror from dry stores (RTA \#2), the CERES lifetime sliver witness mirror that followed all sensor activities, VIIRS Four Mirror Anastigmat (FMA) mirror, other program mirrors and FSS99-500 control samples ${ }^{14}$. The VIIRS RTA witness samples were coated in the same batch, L4G12, as the flight RTA optics using Denton/Quantum's proprietary silver coating process FSS99-500. The Aerospace corporation work was done over the Christmas holiday break and ahead of the VIIRS Deep Dive and Quantum meetings. This information was very encouraging and supportive of a VIIRS local anomaly. However, there were still open questions that needed to be understood before resuming commissioning. So the Deep Dive focused on the items in Table 4 with the following questions to guide the conversation.

- Do we have sufficient information to understand causes for VIIRS VisNIR and SDSM degradation?

- Are there other possible contributing causes?

- Do we agree VIIRS and SDSM degradation are due to different causes?

- Does data and analysis match on-orbit signature for VIIRS and SDSM?

- How should we proceed with VIIRS commissioning?

- What is risk to VIIRS Cryo cooler performance?

- Is there a global satellite risk or is the anomaly local to VIIRS?

- What else can be done to assess the risk to other sensors 


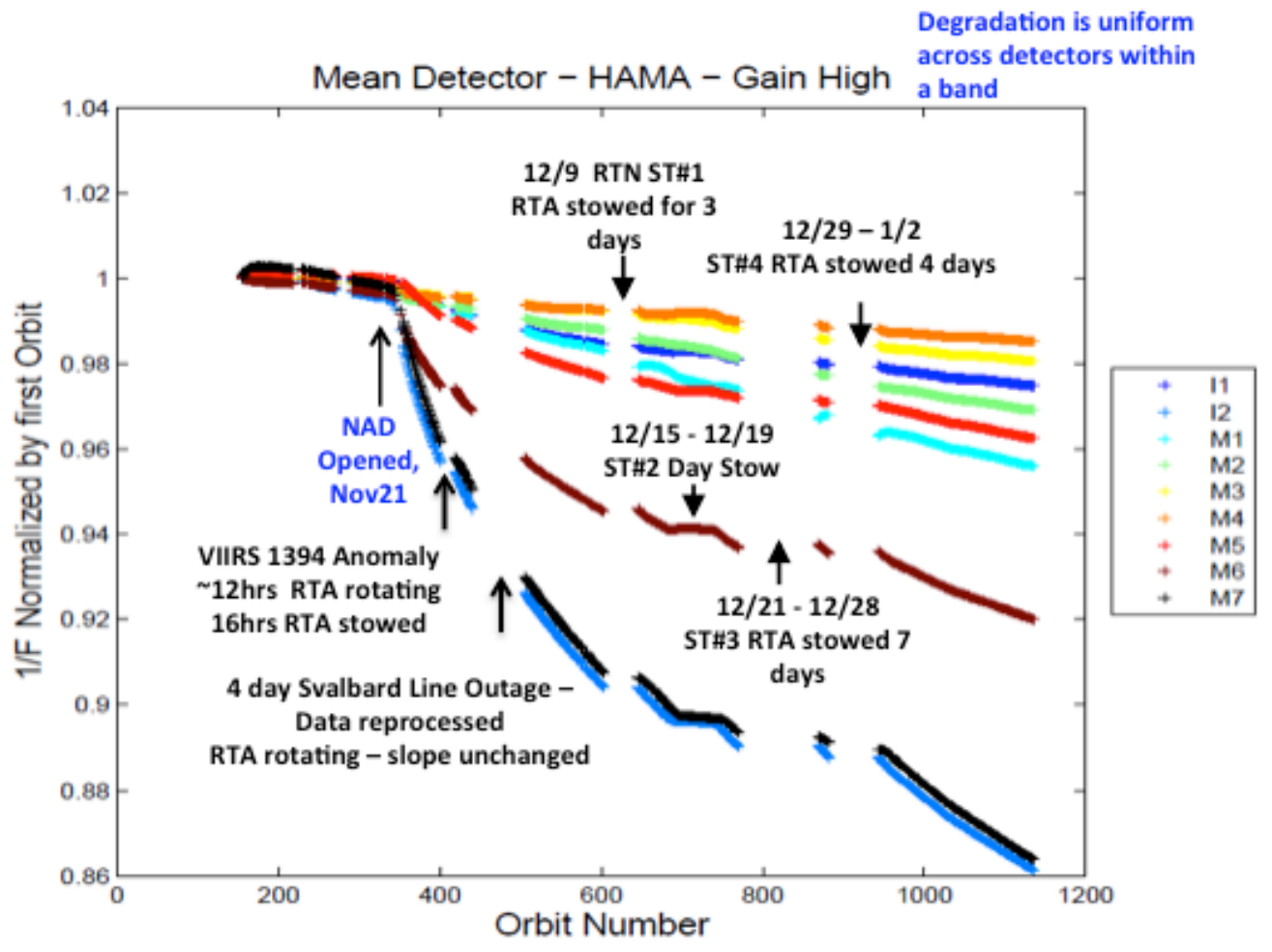

Figure 6: VisNIR response verse orbit time trends 
Table 4: Witness sample testing and face-to-face meetings

\begin{tabular}{|c|c|c|}
\hline Test Activities & Objective & Conclusions / Findings \\
\hline $\begin{array}{l}\text { VIIRS RTA } \\
\text { witness sample } \\
\text { testing \#1 } \\
\text { witness followed } \\
\text { sensor I\&T, \#2 } \\
\text { pristine in dry } \\
\text { storage }\end{array}$ & $\begin{array}{l}\text { Perform molecular evaluation and } \\
\text { Solar radiation tests to determine } \\
\text { potential contaminants } \\
\text { VIRS only (FTIR, GC-MS), } \\
\text { CERES/Control Samples (TOF- } \\
\text { SIM, Solar UV tests) }\end{array}$ & $\begin{array}{l}\text { - VIIRS RTA \#1 \& \#2 shows surface Tungsten in } \\
\text { ToF-SIMS ( } 15-30 \text { Angstroms), \#1 UV } \\
\text { exposure matches on-orbit signature, \#1 Depth } \\
\text { profile shows tungsten on surface and in } \\
\text { outermost layer } \\
\text { - VIIRS } 2^{\text {nd }} \text { RTA sample showed UV saturation } \\
\text { levels comparable to RTA\#1 sample. The } \\
\text { VIIRS FMA witness sample was unchanged } \\
\text { after } 96 \text { hours of UV exposure. }\end{array}$ \\
\hline $\begin{array}{l}\text { VIIRS Deep } \\
\text { dive }(1 / 9-1 / 10)\end{array}$ & $\begin{array}{l}\text { - Communicate information on VIIRS } \\
\text { design, manufacture, test, and } \\
\text { operation to allow ART to accurately } \\
\text { interpret on-orbit data. } \\
\text { - Gather in-depth information on } \\
\text { potential causes. } \\
\text { - Brainstorm causes, additional testing, } \\
\text { plan forward, and risks } \\
\text { - Continue to develop fishbone }\end{array}$ & $\begin{array}{l}\text { - } \quad \text { F2F held January } 9-10 . \text { Build history review } \\
\text { 1/11 - 1/13/2012 } \\
\text { Quantum reported deviation from coating } \\
\text { process for RTA mirrors coat run L4G12 } \\
\text { (source of tungsten). } \\
\text { - } \\
\text { MODIS SDSM \& VIIRS SDSM degradation } \\
\text { have similar signature. Both use the same Si } \\
\text { PIN PD (part \# \& manufacturer match). The } \\
\text { proximate cause was degradation attributed to } \\
\text { radiation. This was confirmed based on NPP/J1 } \\
\text { part testing, spectral signature and analysis }\end{array}$ \\
\hline $\begin{array}{l}\text { Quantum / } \\
\text { Denton Site } \\
\text { Visit (1/31/12) }\end{array}$ & 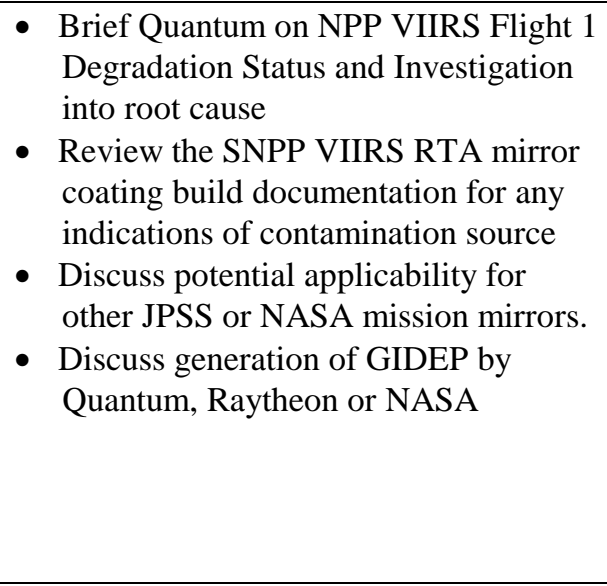 & $\begin{array}{l}\text { - } \quad \text { Site visit on January } 31 . \\
\text { SNPP VIIRS RTA mirrors coated by Denton in } \\
2004 \text { prior to Quantum purchased and ISO } \\
\text { certification in 2007. } \\
\text { - Toured facility coating chamber and reviewed } \\
\text { FSS99-500 process used by Denton } \\
\text { - Reviewed Quantum/Denton's proprietary } \\
\text { FSS99-500 process for a 3-year period. The } \\
\text { root cause was a process deviation for the } \\
\text { VIIRS RTA mirror coating run; which resulted } \\
\text { in tungsten \& tungsten oxide deposition on the } \\
\text { outer mirror surface. Tungsten is known to have } \\
\text { chromogenic properties, which clear up in } \\
\text { atmosphere. }\end{array}$ \\
\hline
\end{tabular}

\section{FISHBONE DEVELOPMENT AND DISPOSITION}

The final VIIRS anomaly fishbone diagram is shown in Figure 7. It identifies the two discrete proximate causes namely a thin (15-30 angstrom) tungsten oxide film contamination on the RTA mirrors impacting the optical throughput for the VisNIR/DNB bands and displacement damage for the Silicon PIN photodiodes used in the SDSM. The fishbone illustrates the various bones that were investigated to varying degrees based on what we learned incrementally through the anomaly investigation. There was a significant amount of effort expended by the team, which is not discussed in this or other papers particularly on the how the various possible causes were discounted. The Root Cause Analysis section touches on the final testing and analysis results that substantiate these proximate causes and identifies the root cause (i.e., process deviation) for the RTA mirror tungsten contamination. 


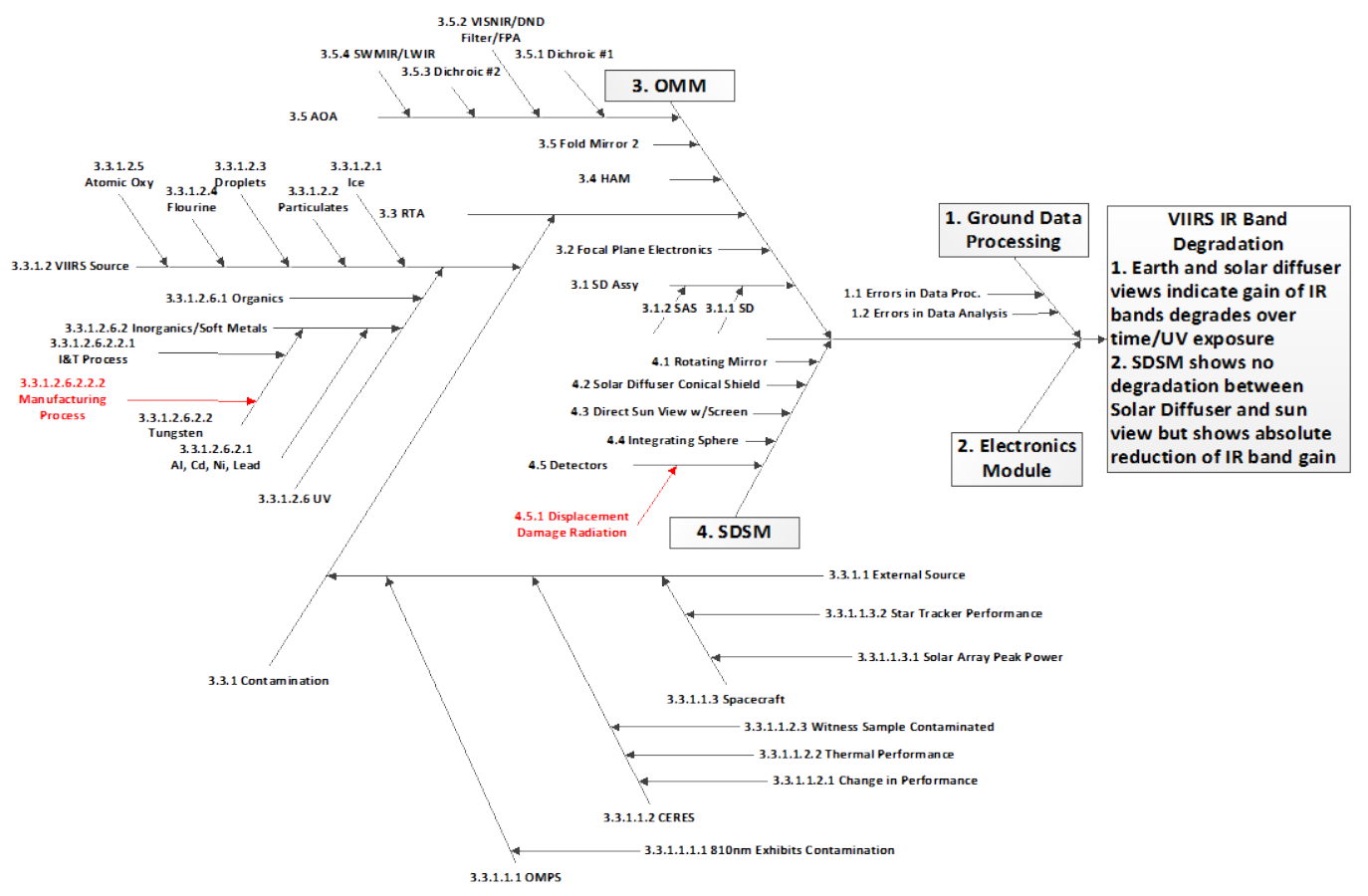

Figure 7: Final VIIRS anomaly fishbone diagram

\section{ROOT CAUSE ANALYSIS AND DETERMINATION}

Contamination was the leading candidate for cause of the degradation anomaly. Contamination migration requires a force. For particles the majority of redistribution takes place during launch. Some redistribution occurs when doors open or mechanisms initially engage. Particulate motion is not constant or temperature dependent. Molecular transport is a function of line-of-sight and temperature. Given the degradation spectral signature was in the NIR, the VIIRS anomaly investigation focused on different sources of molecular contamination.

The observed on-orbit signal degradation for VisNIR bands is correlated with UV exposure ${ }^{2,14,15}$. Witness sample UV exposure tests performed by the Aerospace corporation confirmed reflectance degradation with the same spectral signature as seen on the SNPP VIIRS for two witness samples coated in the same FSS99-500 coating run (i.e., L4G12) as the RTA mirrors. Furthermore, both witness samples showed the presence of tungsten oxides on the surface unlike other FSS99-500 samples which do not show a darkening or the presence of tungsten oxides ${ }^{14}$. Literature shows that tungsten oxides can darken on exposure to UV under vacuum due to the photochromic effect of thin tungsten films ${ }^{16}$. Through discussions with Quantum and review of the coating records, the root cause was traced to a process deviation where the chamber ion gun with tungsten filaments, see Figure 8, was used for oxygen bombardment to increase oxidation in the absorbing layers. The end result was the deposition of tungsten oxide, which is not normally present if the standard FSS99-500 process was followed ${ }^{17}$. As cited in the Bechinger paper ${ }^{16}$, "thin amorphous Tungsten Oxide (W03) films can be switched reversibly from transparent to a blue colored state which has a broad absorption band at $1000 \mathrm{~nm}$, with a shoulder towards the visible range ${ }^{16}$. This matches the observed degradation on-orbit and, through Aerospace corporation testing, the reflectance degradation of the RTA witness mirror samples. In both cases the M7/I2 bands showed the greatest rate of decay. The spectral ranges for these bands are $846-885 \mathrm{~nm}$. Given tungsten's photochromic properties and the absence of VIIRS pre-launch testing with a UV source in vacuum the contamination went undetected. This effect is insidious, as it will rapidly heal in air as soon as the UV radiation is removed and typical thermal vacuum test configurations do not provide in-vacuum UV radiation sufficient to produce a measurable effect. 


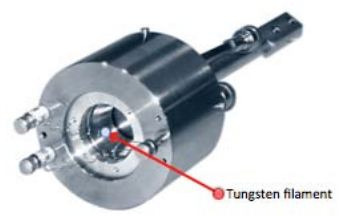

Figure 8: Cold Cathode 105 (CC-105) ion deposition gun

For the VIIRS SDSM, the spectral degradation signature was similar to the VIIRS VisNIR degradation but not driven by solar exposure. This departure supported the theory for a second proximate root cause. Through collaboration between Raytheon and the MODIS/VIIRS science team, the VIIRS SDSM and MODIS SDSM degradation signatures were found to be very similar. Review of the MODIS and VIIRS showed that both designs were similar and they both used the same Silicon PIN photodiodes (i.e., same part number and manufacturer). SNPP and JPSS-1 VIIRS detector radiation testing was performed at three levels. The degradation at the $900 \mathrm{~nm}$ response was determined to be similar to that observed on-orbit. With SNPP's orbit higher than EOS, the radiation environment is roughly $2 \mathrm{x}$ over the MODIS/Aqua orbit for both ionizing dose and proton fluence. Figure 9 shows the similarities in response degradation on-orbit for MODIS and VIIRS. Figure 10 compares the on-orbit degradation to those measured for the detector responsivity with exposure to high-energy particle radiation.

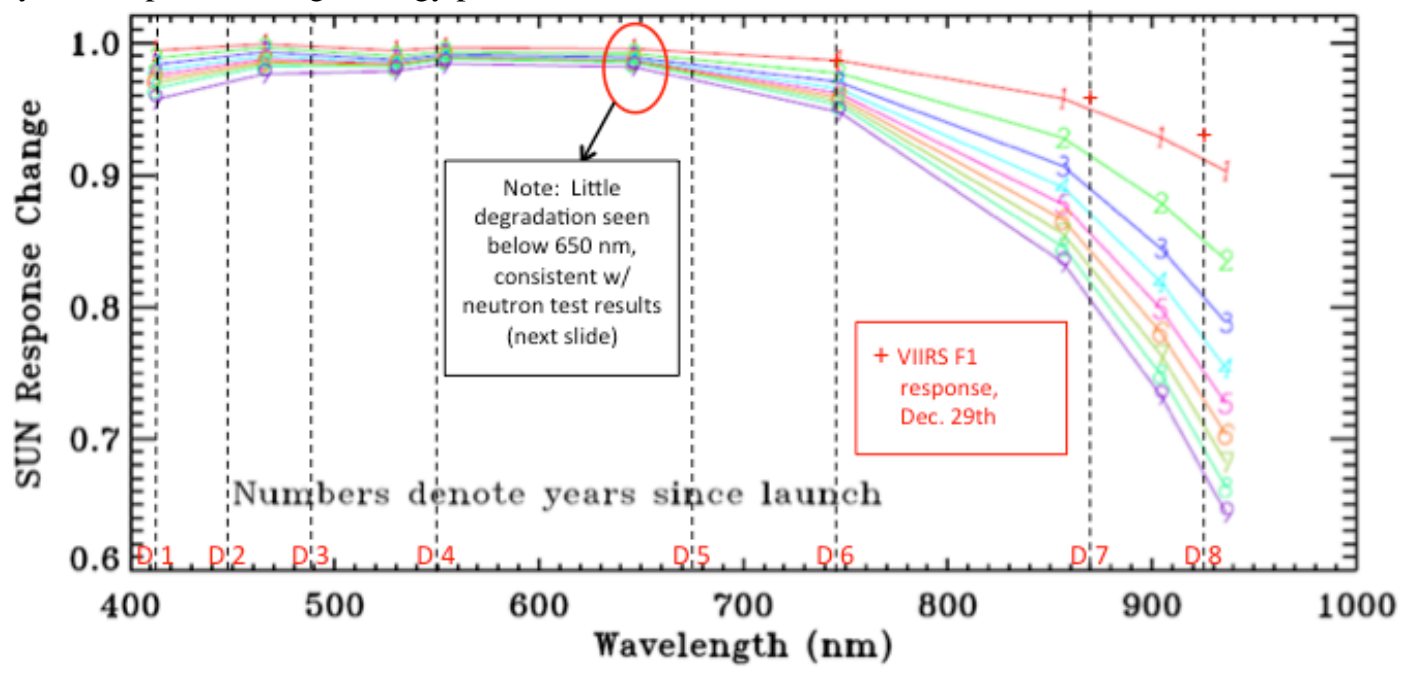

Figure 9: VIIRS verses MODIS Aqua SDSM response degradations

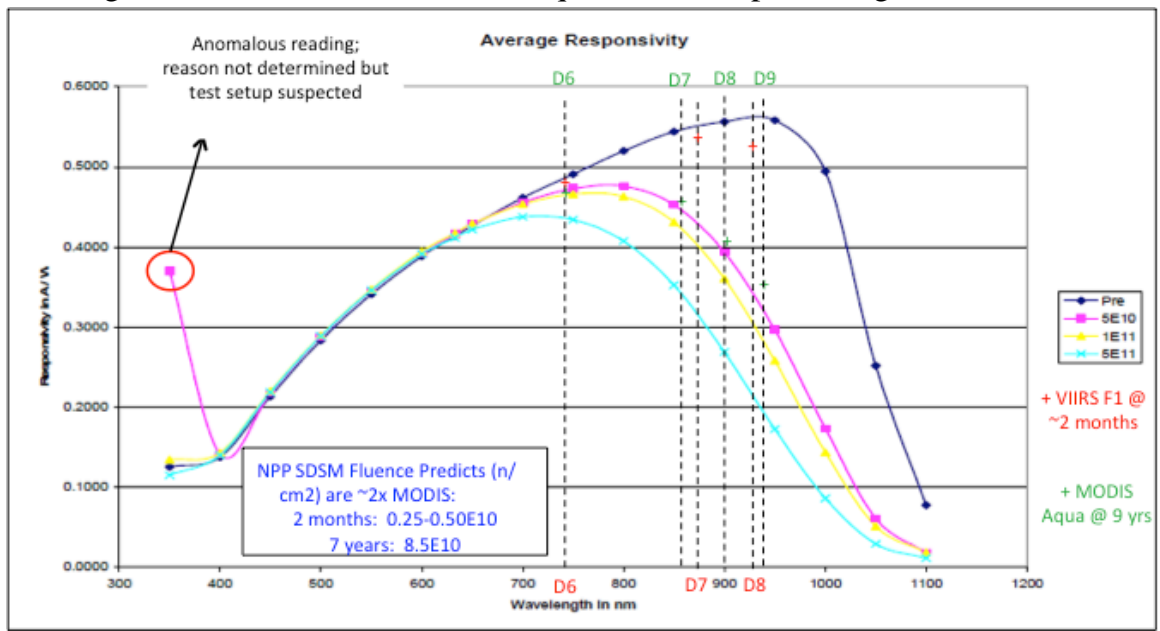

Figure 10: VIIRS and MODIS SDSM response degradations verses neutron test results 


\section{LESSONS LEARNED AND CORRECTIVE ACTION}

Table 5 provides a summary of the lesson learned and their applicability to the VIIRS anomaly investigation. The lessons include lessons that should be followed as good practices (e.g., test at the lowest assembly level as possible, test as you will fly, and pay close attention to slight differences when using heritage designs). It also includes a few new process lessons (e.g., improved processes implemented by Quantum, and contract changes for anomaly notifications where multiple subcontracts are used).

Quantum released a Government - Industry Data Exchange Program (GIDEP) lesson learned report as a result of the investigation ${ }^{17}$. An excerpt is included here

Quantum GIDEP Lessons Learned: "After the low reflectance readings on the mirrors were attributed to oxygen deficiency from lower pressure due to overnight pumping, the practice of pumping the chamber overnight was no longer performed. Improved process controls were implemented to include establishing minimum and maximum vacuum pressure ranges, recovery time after glow discharge, regular maintenance cycles and improved chamber preparation checklists. The pressure limits are stated in the SOP and on the operator run sheet as an alert to the coating chamber operator to suspend any coating run that does not meet the criteria specified before proceeding with the coating run. We now know that a small amount of tungsten is deposited during the post-coating ion bombardment treatment that causes degradation in reflectance under specific limited conditions. During the review of our past records, it was confirmed that the ion bombardment post coating treatment has not been attempted on any other FSS99 coatings since this occurrence and will not be utilized in the future".

There was a possibility that the VIIRS SDSM degradation could have been detected during the EOS MODIS campaign. However, there was a design related feature in the MODIS SDSM system, which was not discovered until after launch. This led to large ripples in SDSM's Sun view responses (from all detectors). Much of the attention was given to a design change (fix) for SNPP VIIRS SDSM in order to minimize the ripples seen in by MODIS SDSM. At the same time, not enough effort was made or attention was given to fully understand why the changes in SDSM detector responses are larger at NIR longer wavelengths. In terms of design and pre-launch characterization, lessons from MODIS and SNPP VIIRS SDSM on-orbit performance will significantly benefit JPSS and other future programs.

Table 5: Summary of applicable lessons learned for the VIIRS anomaly

\begin{tabular}{|c|c|c|}
\hline No. & Lesson Learned & VIIRS Applicability \\
\hline 1 & $\begin{array}{l}\text { Understand Test As You } \\
\text { Fly (TAYF) exceptions } \\
\text { and potential risks }\end{array}$ & $\begin{array}{l}\text { - TAYF exception for UV testing and measurement in vacuum of } \\
\text { VIIRS mirror reflectance could have identified contamination prior to } \\
\text { launch } \\
\text { - For SNPP, the witness mirrors were repeatedly measured in } \\
\text { atmosphere. Given tungsten oxide is chromogenic the anomaly went } \\
\text { undetected prior to launch. } \\
\text { - Special test equipment required was available at the Aerospace } \\
\text { corporation; which accelerated confirmation of root cause during the } \\
\text { anomaly investigation }\end{array}$ \\
\hline 2 & $\begin{array}{l}\text { Process changes should } \\
\text { be thoroughly evaluated } \\
\text { for possible undesired } \\
\text { secondary effects }\end{array}$ & $\begin{array}{l}\text { - After the low reflectance readings on the mirrors were attributed to } \\
\text { oxygen deficiency from lower pressure due to overnight pumping, the } \\
\text { practice of pumping the chamber overnight was no longer performed }{ }^{3} \text {. } \\
\text { - Reflectance improved by ion bombardment with oxygen to increase } \\
\text { oxidation of silica and densification of protective layers. This } \\
\text { introduced tungsten oxides on the mirror surface. } \\
\text { - Improved process controls were implemented at Quantum; including } \\
\text { ISO certification }\end{array}$ \\
\hline 3 & $\begin{array}{l}\text { Use of travelers, } \\
\text { certification logs, and } \\
\text { build documentation can }\end{array}$ & $\begin{array}{l}\text { Denton build documentation provided confirmation of process } \\
\text { deviation that led to use of oxidation of outer mirror coating using } \\
\text { tungsten gun }\end{array}$ \\
\hline
\end{tabular}




\begin{tabular}{|l|l|ll|}
\hline & $\begin{array}{l}\text { provides valuable insight } \\
\text { for investigations }\end{array}$ & $\bullet$ & $\begin{array}{l}\text { For Quantum it provided valuable information to state this was } \\
\text { isolated to SNPP VIIRS and not other coating runs }\end{array}$ \\
\hline 4 & $\begin{array}{l}\text { Anomaly resolution } \\
\text { should include } \\
\text { appropriate } \\
\text { documentation and } \\
\text { notification }\end{array}$ & $\bullet \begin{array}{l}\text { FSS99-500 standard process deviation was not sufficiently elevated } \\
\text { through subcontracts to government. Nor was it sufficiently } \\
\text { documented in delivery documentation }\end{array}$ \\
\hline 5 & $\begin{array}{l}\text { Where heritage designs } \\
\text { are used for future designs contract changes put in place to elevate deviations to } \\
\text { gnderstand differences in } \\
\text { application and } \\
\text { environment }\end{array}$ & $\begin{array}{l}\text { SDSM degradation existed on EOS MODIS (same manufacturer and } \\
\text { part as VIIRS SDSM) but degradation was slower given lower } \\
\text { radiation environment in EOS mission orbit. }\end{array}$ \\
\hline
\end{tabular}

There is no corrective action that is possible to mitigate either of the proximate causes for the degradation observed on-orbit. However, the problems have been isolated to VIIRS and this allowed for the SNPP commissioning activities to complete successfully in early March. All sensors are performing exceptionally well, with special attention being focused on monitoring VIIRS degradation performance. As part of the Root Cause Analysis Raytheon completed modeling of the degradation and their results compare favorably to observed on orbit performance $^{13}$. The modeling predicts that the VIIRS signal to noise (SNR) performance is sufficiently large such that even at the currently extrapolated point of the degradation at the end of mission, the VIIRS performance is still expected to be within specification over its mission design life of 7 years. The Science team will continue to trend on-orbit NPP VIIRS and SDSM performance and predict future performance for the life of the mission. The science team has also implemented ground system algorithms changes to accommodate the changing VIIRS response.

With the transition of SNPP operational responsibility and sustainment now under the JPSS Program several activities associated with completing the investigation and applying the lessons for the JPSS VIIRS have been implemented. These include

- Raytheon Root Cause/Corrective Action investigation is complete and the results have been provided to the government

- The Fishbone analysis and documentation are now completed

- Contract changes to improve notification for deviations from qualified process have been implemented

- JPSS-1 VIIRS has conducted UV exposure testing in excess of 700 hours with the JPSS-1 mirror witness samples with the reflectivity measured by the Aerospace Corporation while still in vacuum. The spectral response of the witness mirrors showed no UV degradation.

- Quantum has issued a GIDEP Lessons Learned Report ${ }^{3}$ and implemented process changes to prevent future reoccurrence of this type of anomaly during their mirror coating process

Additionally, the NASA GSFC Optics Branch is working to develop and publish additional information and guidance (e.g., testing to perform, process control) for missions that have or will use silver reflective mirrors.

\section{CONCLUSION}

The SNPP VIIRS on-orbit degradation presented many challenges that at times were very complex and seemingly conflicting. The ability of the anomaly team to be inquisitive, flexible, competent and above all relentless led to the timely, confident detection and identification of two different proximate causes that had similar spectral degradation. It also aided in determining root cause for the VisNIR/DNB degradation.

In hindsight, one could postulate that the identification or detection of these proximate causes may have been possible, pre-launch, if additional effort was applied to perform testing or analysis in a flight like manner closer to what SNPP is experiencing. However, there are often other technical and programmatic challenges that must factor into the planning and risk management process. For the VisNIR/DNB degradation it would have required additional testing with special 
test equipment to simulate the anticipated SNPP UV exposure in vacuum; including measurement of reflectance before returning back to atmosphere. Similarly, for the SDSM it would have required extrapolation of radiation testing or comparison to EOS performance with adjustments for the higher radiation dose environment that SNPP.

The VIIRS VisNIR/DNB degradation was conclusively traced to the photochromic effects of tungsten oxide on the SNPP VIIRS RTA mirror surfaces. Through inspection of the Denton build documentation it was isolated to a 1-time process deviation (i.e. root cause) to improve surface reflectance during the mirror coating process. Raytheon has modeled the degradation and it compares well with the VIIRS on-orbit performance ${ }^{13}$. The science team will continue to trend VIIRS performance for the mission life against the Raytheon model. Given this identified risk, the JPSS Project conducted testing for the JPSS-1 VIIRS RTA mirrors. The results show there is no tungsten contamination present. The VIIRS SDSM proximate cause was degradation due to displacement damage in the Silicon PIN photodiodes induced by the $\sim 2$-times radiation environment, both ionizing dose \& equivalent proton fluence, when compared to the MODIS/Aqua orbit. Through a very conservative analysis by Raytheon they determined that the SDSM's SNR margins at 7 years are extremely healthy (e.g., greater than 200\%). The radiation effects are in family with the effects observed with MODIS SDSM (i.e., same photodiode manufacturer and part number) but to lesser extent given the lower radiation environment for MODIS. These also are similar to the CERES silicon PIN photodiodes degradation that has been exhibited prior EOS CERES missions.

Given these effects could not be mitigated on-orbit, SNPP VIIRS will continue to experience a gradual reduction in the optical throughput. However, it will continue to meet science performance needs beyond the SNPP mission life. As shown in Figure 11, the measured and predicted normalized gains will remain above the level where the SNR performance becomes noncompliant for all bands beyond 2019.

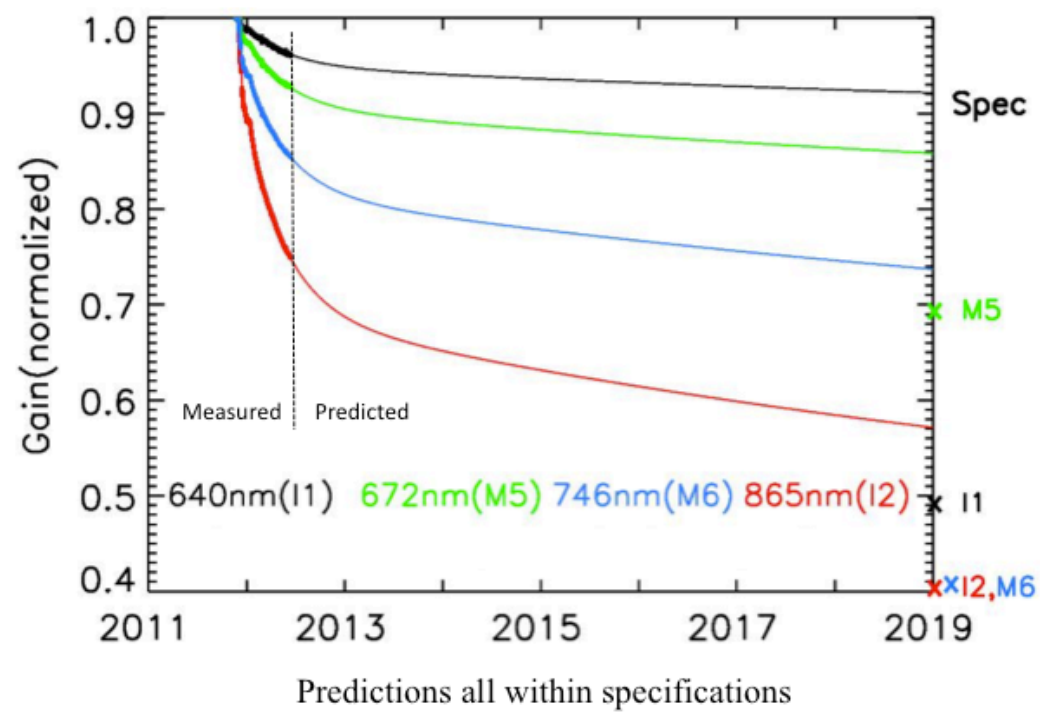

Figure 11: VIIRS performance predictions for the SNPP mission lifetime

\section{REFERENCES}

[1] Gleason, J., "NPP launches an Earth Observing Mission - Early on-orbit performance and Initial Results,” $18^{\text {th }}$ Conference on Satellite Meteorology Oceanography and Climatology First Joint AMS-Asia Satellite Meteorology Conference at the American Meteorological Society Annual Conference, New Orleans, (2012)

[2] De Luccia, F., Moyer, D., Johnson, E., Rausch, K., Lei, N., Chiang, K., Xiong, X., and Fulbright, J., Haas, E., Iona, G. "Discovery and characterization of on-orbit degradation of the Visible Infrared Imaging Radiometer Suite (VIIRS) Rotating Telescope Assembly (RTA),” SPIE Annual Meeting San Diego, paper 8510-46, (2012)

[3] Barnes, W., Pagano,T., and Salomonson, V., "Prelaunch characteristics of the Moderate Resolution Imaging 
Spectroradiometer (MODIS) on EOS-AM1,” IEEE Transactions on Geoscience and Remote Sensing, 36, 1088-1100, (1998)

[4] Barnes, W., Xiong, X., Guenther, B., and Salomonson, V., "Development, Characterization, and Performance of the EOS MODIS Sensors’,” SPIE Annual Meeting San Diego, Vol. 5151, 337-345, doi: 10.1117/12.504818, (2003)

[5] Xiong, X., Erives, H., Xiong, S., Xie, X., Esposite, J., Sun, J., and Barnes, W., "Performance of Terra MODIS Solar Diffuser and Solar Diffuser Stability Monitor,” SPIE Annual Meeting San Diego, Vol. 5882, 58820S, doi:

10.1117/12.615334, (2005)

[6] Xiong, X., Sun, J., Barnes, W., Salomonson, V., Esposito, J., Erives, H., and Guenther, B., "Multi-year On-orbit Calibration and Performance of Terra MODIS Reflective Solar Bands," IEEE Transactions on Geoscience and Remote Sensing, Vol. 45, No. 4, 879-889, (2007)

[7] Xiong, X., Sun, J., Xie, X., Barnes, W., and Salomonson, V., “On-Orbit Calibration and Performance of Aqua MODIS Reflective Solar Bands,” IEEE Transactions on Geoscience and Remote Sensing, paper 48(1) 535-546, (2010)

[8] Barnes, W., Brown, S., Lykke K., Guenther, B., Xiong, X., and Butler, J., “Comparison of two methodologies for calibrating satellite instruments in the visible and near infrared Earth Observing Missions and Sensors: Development, Implementation, and Characterization,” SPIE Meeting, 78620C-19, doi: 10.1117/12.868356, (2010)

[9] Novitsky, E., Herbst, S., Young, J., Puschell, J., Fest, E., and Guenther, B., "Polarization sensitivity of Visible Infrared Imager Radiometer Suite (VIIRS) Flight Unit 1,” SPIE Annual Meeting San Diego, paper 8516-22, (2012)

[10] Kent, C., Lambeck, R., Iona, G., Lykke, K., Brown, S., Gonzales, T., and McCarthy, J., "Spacecraft-level End-toend Testing of the NPP VIIRS Input Ports,” Calibration Conference Space Dynamics Laboratory, Logan, UT, (2010)

[11] Fuqua, P., "Laboratory testing of interference filters to assess potential for optical cross-talk," Calibration Conference, Space Dynamics Laboratory, Logan, UT, (2007)

[12] Guenther, B. "Application of laser-source-based calibration for VIIRS for ultra-high-accuracy spectoradiometric calibration,” SPIE Annual Meeting San Diego, paper 8372-13, (2012)

[13] Murgai V., "Program Data Archive - VIIRS Throughput Degradation Modeling due to UV Exposure Presentation to NASA Root Cause Team March 29, 2012,” Raytheon Engineering Notebook (ENB) 2-08-NPP-200 revision A, (2012)

[14] Fuqua P., Barrie J., Meshishnek M., Ciofalo M., Chu C., Chaney J., Moision R., Graziani, L., "Root cause determination of on-orbit degradation of the VIIRS rotating telescope assembly," SPIE Annual Meeting San Diego, paper 8510-47, (2012)

[15] Murgai V., "Program Data Archive - Mirror Degradation due to UV Exposure: Root Cause,” Raytheon Engineering Notebook (ENB) 3-10-J1-015, (2012)

[16] Bechinger C., "On the fundamental role of oxygen for the photochromic effect of WQ3,” Journal of Applied Physics, Citation: J. Appl. Phys. 74, 4527, doi: 10.1063/1.354370, (1993)

[17] Childers C., "Lessons Learned for Ion Bombardment of FSS99 Silver Coating," Government Industry Data Exchange Program (GIDEP), LL-U-12-001, (2012)

\section{ACKNOWLEDGMENTS}

The content above includes documentation and activity summaries that span a decade. Some of these activities are documented in published papers, but a fair amount is in the form of stand-alone technical notes (easily understood) and 
project review slide packages that are archived. Looking through these documents one is reminded of all of the folks, who worked not only on the space sensors, but on the ground test equipment as well. Thanks go to them. 